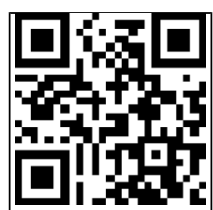

Editor's choice Scan to access mor free content
${ }^{1}$ Department of Pediatrics, Mayo Clinic, Rochester, Minnesota, USA ${ }^{2}$ Department of Pediatrics, Division of Pediatric Cardiology, Mayo Clinic, Rochester, Minnesota, USA ${ }^{3}$ Department of Medicine, Division of Cardiovascular Diseases, Mayo Clinic, Rochester, Minnesota, USA ${ }^{4}$ Department of Molecular Pharmacology \& Experimental Therapeutics, Mayo Clinic, Rochester, Minnesota, USA

\section{Correspondence to} Dr Jonathan N Johnson, Pediatric Cardiology, 200 1st St. SW, Gonda 138-SW, Rochester, MN 55905, USA; johnson.jonathan@mayo.edu

Accepted 8 November 2015

\title{
Electrocardiographic abnormalities in elite high school athletes: comparison to adolescent hypertrophic cardiomyopathy
}

\author{
Alex J Thompson, ${ }^{1}$ Bryan C Cannon, ${ }^{2}$ Philip L Wackel, ${ }^{2}$ Justin M Horner, ${ }^{2}$ \\ Michael J Ackerman, 2,3,4 Patrick W O'Leary, ${ }^{2,3}$ Benjamin W Eidem, ${ }^{2,3}$ \\ Jonathan N Johnson ${ }^{2,3}$
}

\begin{abstract}
Background In athletes, ECG changes from physiological cardiac remodelling are common but can overlap with findings from a pathological disorder. We compared ECG findings in a group of elite high school athletes to a cohort of adolescents with hypertrophic cardiomyopathy (HCM).
\end{abstract}

Methods/results We prospectively performed 15-lead ECGs and echocardiograms in 147 elite high school athletes. Student-athlete ECGs were compared in blinded fashion to ECGs of 148 adolescents with HCM of similar age and ethnicity. Standard ECG hypertrophy criteria and established expert opinion guidelines (European Society of Cardiology, ESC and Seattle criteria) were analysed. All student-athletes had normal echocardiograms. Overall, 77/147 (52\%) of student-athletes met standard ECG criteria for ventricular hypertrophy compared to $126 / 148(85 \%)$ adolescents with HCM $(p<0.0001)$. There were 112/148 (76\%) adolescents with HCM who had pathological Q-waves, T-wave inversion and/or ST-segment depression compared to $1 / 147(1 \%)$ athletes $(p<0.0001)$. Most patients with HCM $(84 \%, 124 / 148)$ had $\geq 1$ abnormal ECG finding(s) according to Seattle criteria, compared to $1 \%$ of student-athletes (2/147). Similarly, 130/148 (88\%) patients with HCM met group2 ESC criteria (abnormal), compared to $36 / 147$ (24\%) student-athletes $(p<0.0001)$.

Conclusions Over $50 \%$ of elite high school athletes with echocardiographically confirmed normal hearts satisfied standard voltage criteria for ventricular hypertrophy. Pathological Q-waves, T-wave inversion or ST-segment depression were most helpful in distinguishing adolescents with HCM from normals. Both ESC and Seattle criteria successfully stratified the student-athlete and HCM cohorts, however each had a false-negative rate $>10 \%$ for the HCM cohort. The Seattle criteria demonstrated a significantly lower false-positive rate (1\%) than the ESC criteria (24\%).

Application of the Seattle criteria produces a considerably lower false-positive rate with minimal reduction in sensitivity compared to the ESC criteria and should be considered if screening programmes in young athletes are conducted.

\section{INTRODUCTION}

Athletic cardiac screening in the young has been studied widely, and its methodology and role continues to be actively debated in the USA. ${ }^{12}$ Studies in countries including Italy, Japan and Israel have provided varied results with some programmes reporting an apparent reduction in the frequency of sudden death while others failed to show a significant mortality benefit following the addition of an ECG to the screening programme. ${ }^{3}{ }^{4}$ Recent publications have examined the feasibility of athletic screening in the USA, ${ }^{5}$ however, the feasibility and cost-effectiveness of these programmes nationally remains in question. ${ }^{1}{ }^{7-9}$

In trained athletes, ECG aberrations are common. ${ }^{10}$ These may include prominent precordial voltages, T-wave inversions, deep Q-waves and repolarisation abnormalities, and have been reported to occur in as many as $40-80 \%$ of trained athletes. ${ }^{11-14}$ These abnormalities often prompt evaluation for underlying cardiac pathology, which can include studies such as exercise stress tests, echocardiography and even genetic testing. The European Society of Cardiology (ESC) published guidelines in 2010 to help distinguish normal ECG findings in athletes from more concerning ECG findings that require further investigation. ${ }^{12}$ In 2012, an international group of experts developed the Seattle criteria with similar goals. ${ }^{13}$

Hypertrophic cardiomyopathy (HCM) affects 1 in 500 adults. ${ }^{15}$ It is defined as unexplained left ventricular hypertrophy without dilation of the ventricular chambers, in the absence of another disease capable of causing the hypertrophy. ${ }^{16} \mathrm{HCM}$ is characterised by profound heterogeneity as patients can display varying degrees of hypertrophy, fibrosis and left ventricular outflow tract (LVOT) obstruction. ${ }^{15}$ Similarly, the clinical presentation can vary from asymptomatic to end-stage heart failure or sudden death. ${ }^{17}{ }^{18} \mathrm{HCM}$ is one of the most common cardiovascular causes of sudden death in athletes, and as such is an important diagnosis that needs to be identified by preparticipation screening in the USA. ${ }^{1}$ In our study, we sought to compare ECG findings in a cohort of elite high school athletes to a cohort of adolescents with $\mathrm{HCM}$, in an effort to evaluate currently published athlete screening ECG criteria and identify ECG changes more consistent with underlying cardiac pathology.

\section{METHODS}

\section{Screening}

In this Institutional Review Board-approved prospective study, we offered cardiovascular screening to all students between grades 7 and 12 (ages 12- 
19) at Shattuck St. Mary's School (SSM), a private school located in Faribault, Minnesota, USA. SSM is an institution known for a variety of academic and elite athletic programmes, but is known most for its ice hockey, soccer and figure skating athletic programmes. The student-athletes at SSM participate in a rigorous schedule of athletic training, typically involving at least $4 \mathrm{~h}$ of practice or competitions daily. Many of these students go on to play National Collegiate Athletic Association (NCAA) Division I and professional sports. Of the 415 enrolled students at SSM at the time of the study, 187 (45\%) agreed to participate. Participation was voluntary and specific information regarding reasons of non-participation was not elicited or available. We obtained both signed parental consent as well as student assent for participation. All students were notified of the results of their evaluation by mail after completion of the study. Forty students were not participating in school athletic programmes, and were excluded from this study.

All student-athletes underwent a limited cardiovascularfocused physical examination, and had their height, weight, pulse rate and blood pressure recorded. We performed a standard 15-lead ECG on each student-athlete, and interpreted them as discussed below. We also performed complete twodimensional, spectral and Colour Doppler transthoracic echocardiograms. All echocardiograms were stored digitally and were interpreted by a single paediatric echocardiographer (BWE). The full cardiovascular evaluation took approximately $30 \mathrm{~min}$ to perform for each student. For the purposes of this study, we will focus on the ECG screening results.

\section{ECG measurements}

We used the following criteria for assessment of ECG abnormalities. Right atrial enlargement was defined as a $p$ wave height of $\geq 3 \mathrm{~mm}$ in lead II, III or aVF. Left atrial enlargement was defined as a prolonged $\mathrm{p}$ wave duration $\geq 120 \mathrm{~ms}$ in lead I or II with negative portion of $\mathrm{p}$ wave $\geq 1 \mathrm{~mm}$ deep and $40 \mathrm{~ms}$ in duration in lead V1. Left axis deviation was defined as a frontal plane QRS of less than $-30^{\circ}$ and right axis deviation was defined as $\geq 120^{\circ}$. Abnormal T-waves were defined as T-wave inversion in two adjacent leads for V2-V6, II and aVF, or I and aVL, excluding V1, III and aVR. Q waves were defined as abnormal when $>3 \mathrm{~mm}$ deep or $40 \mathrm{~ms}$ in duration in $\geq 2$ leads excluding III and aVR per the Seattle criteria. QT values were measured manually from a 12-lead ECG, and a QTc was calculated using the standard Bazett's formula. ${ }^{19}$ When possible, leads II or V5 were used for QT interval measurement. Prolonged QT was defined as QTc $>470 \mathrm{~ms}$ in males and $>480 \mathrm{~ms}$ in females since these thresholds represent the genderspecific 99th centiles. Short QT was defined as $<380 \mathrm{~ms}$ per ESC criteria and $<320 \mathrm{~ms}$ per Seattle criteria. Pre-excitation was defined by a short PR interval $(<120 \mathrm{~ms})$ with slurring of the QRS and prolonged QRS segment.

Similar to prior guidelines, ${ }^{12}$ Sokolow-Lyon criteria were used for determination of left ventricular hypertrophy (LVH) or right ventricular hypertrophy $(\mathrm{RVH})$. We considered an ECG suggestive of $\mathrm{LVH}$ if the $\mathrm{S}$-wave deflection in lead V1 plus $\mathrm{R}$-wave deflection in lead V5 or V6 (whichever was greater) was equal to or greater than $35 \mathrm{~mm}$. An ECG was suggestive of $\mathrm{RVH}$ if the R-wave deflection in lead V1 plus S-wave deflection in lead V5 was greater than $10.5 \mathrm{~mm}$ per ESC criteria. To meet Seattle criteria, concomitant right axis deviation was required. An ECG was suggestive of biventricular hypertrophy if the total deflection of the QRS complex in lead V4 was greater than $50 \mathrm{~mm}$, or if both LVH and RVH criteria were met.

\section{HCM cohort}

The SSM students-athletes' ECG results were compared to ECGs of a retrospective cohort of 148 adolescents with HCM with similar age and ethnicity who were followed at Mayo Clinic from 1 January 1983 to 31 December 2013. Patients with 'syndromic' causes for HCM (including Noonan syndrome, Leopard syndrome, etc) were excluded. Patients were considered to have HCM if they had a clinical diagnosis for HCM made by a paediatric cardiologist and septal or posterior wall thickness $\geq 13 \mathrm{~mm}$ or $\geq 1$ finding(s) of LVOT, systolic anterior motion, diastolic dysfunction, mitral regurgitation, left atrial enlargement or were an apical variant. All patients with previous cardiac surgery other than implantable cardiac defibrillator placement were excluded. Patients who had a paced rhythm at the time of ECG were excluded.

\section{ECG interpretation}

The ECGs of the student athletes and the patients with HCM were combined in random order and then interpreted by two paediatric electrophysiologists (BCC and PLW) independently. Disagreements were adjudicated by a third paediatric cardiologist (JNJ). Thus, all interpreters were blinded to which cohort (student-athlete vs HCM) that each ECG belonged, and blinded to the results of any other testing (clinical examination or echocardiography).

\section{Statistical analysis}

JMP 10.0.0 (SAS Institute, Cary, North Carolina, USA) was used to analyse the data. All continuous variables were reported as the mean \pm SD. Means were analysed and compared using a pooled $t$ test. Proportions were analysed using a Pearson $\chi^{2}$ test. For proportions where one of the variables included a frequency of $\leq 5$, a Fisher exact test was used. A $p$ value $<0.05$ was considered to be significant.

\section{RESULTS}

\section{Student athlete cohort}

One hundred and forty-seven student athletes from SSM were included in this study (average age $=16.0 \pm 1.3$ years, 88 males, table 1).

Importantly, all athletes had normal echocardiograms and consequently, the ECG analyses represent an investigation into the frequency of and basis for false-positives in terms of ECG findings that might have predicted a structurally abnormal heart. Specific echocardiographic data for both the student-athlete and HCM cohorts are reported in table 2.

Table 1 Demographics

\begin{tabular}{|c|c|c|c|}
\hline Demographics & $\begin{array}{l}\text { Student-athletes } \\
(\mathrm{N}=147)\end{array}$ & $\begin{array}{l}\text { Adolescents with } \\
\text { HCM }(\mathrm{N}=148)\end{array}$ & $\begin{array}{l}\text { p Value } \\
\text { (athletes vs } \\
\text { HCM) }\end{array}$ \\
\hline Age & $16.0 \pm 1.3$ & $16.1 \pm 1.8$ & 0.54 \\
\hline Gender & $\begin{array}{l}88 \text { male }(60 \%) \\
59 \text { female }(40 \%)\end{array}$ & $\begin{array}{l}107 \text { male }(72 \%) \\
41 \text { female }(28 \%)\end{array}$ & 0.02 \\
\hline BSA & $1.77 \pm 0.2$ & $1.92 \pm 0.3$ & $<0.0001$ \\
\hline Ethnicity* & $\begin{array}{l}97 \text { white }(90 \%) \\
11 \text { othert }(10 \%)\end{array}$ & $\begin{array}{l}107 \text { white }(93 \%) \\
8 \text { other }(7 \%)\end{array}$ & 0.43 \\
\hline \multicolumn{4}{|c|}{$\begin{array}{l}\text { *Unable to obtain ethnicity data on } 39 \text { (27\%) athletes and } 33 \text { (22\%) adolescents } \\
\text { with HCM. } \\
\text { tOther ethnicities include Asian (2), African-American (3) and Hispanic (6). } \\
\text { ‡Other ethnicities include African-American (2), Hispanic (4), Indian (1) and Native } \\
\text { American (1). } \\
\text { BSA, body surface area; HCM, hypertrophic cardiomyopathy. }\end{array}$} \\
\hline
\end{tabular}


Table 2 Echocardiographic data

\begin{tabular}{lccc}
\hline Category & $\begin{array}{l}\text { Student- } \\
\text { athletes }\end{array}$ & $\begin{array}{l}\text { Adolescents } \\
\text { with HCM }\end{array}$ & p Value \\
\hline LV septal wall thickness $(\mathrm{cm})$ & $0.9 \pm 0.1$ & $2.4 \pm 1.0$ & $<0.0001$ \\
LV posterior wall thickness $(\mathrm{cm})$ & $0.8 \pm 0.1$ & $1.4 \pm 0.4$ & $<0.0001$ \\
LV end diastolic diameter $(\mathrm{cm})$ & $5.1 \pm 0.4$ & $4.3 \pm 0.6$ & $<0.0001$ \\
LV end systolic diameter $(\mathrm{cm})$ & $3.2 \pm 0.3$ & $2.3 \pm 0.5$ & $<0.0001$ \\
Ejection fraction & $0.60 \pm 0.06$ & $0.70 \pm 0.08$ & $<0.0001$ \\
LV mass $(\mathrm{gm})$ & $159 \pm 40$ & $394 \pm 195$ & $<0.0001$ \\
LV mass index $\left(\mathrm{gm} / \mathrm{m}^{2}\right)$ & $89 \pm 18$ & $206 \pm 96$ & $<0.0001$ \\
\hline
\end{tabular}

LV, left ventricle; HCM, hypertrophic cardiomyopathy.

Of these 147 student-athletes, 77 (52\%) met voltage criteria for LVH (31\%), RVH (13\%) or biventricular hypertrophy (BVH) (9\%) on ECG. Male athletes more commonly met hypertrophy criteria $(68 / 88,78 \%)$ compared to female athletes $(9 / 59$, $15 \%)(\mathrm{p}<0.0001)$.

\section{Adolescent HCM cohort}

One hundred forty-eight adolescents with known HCM were included in this study (average age $=16.1 \pm 1.8$ years, 107 male, table 1). Echocardiographic data were obtained for $147 / 148$ of the patients on or near the date of ECG. These patients had an average LV septal wall thickness of $2.4 \mathrm{~cm}$ and LV mass index of $206.3 \mathrm{gm} / \mathrm{m}^{2}$. One hundred twenty-six patients $(85 \%)$ met standard ECG criteria for LVH (32\%), RVH $(23 \%)$ or BVH (30\%). Males with HCM more commonly met hypertrophy criteria $(96 / 107,90 \%)$ compared to females $(30 / 41,73 \%$, $\mathrm{p}=0.01)$. Approximately $3 \%(5 / 148)$ of the patients with HCM had completely 'normal' ECGs, with 16 of the 22 that lacked voltage criteria for hypertrophy showing at least one of the following: pre-excitation, abnormal QRS axis, pathological Q-waves, T-wave inversion and/or ST-segment depression.

\section{Student-athletes versus adolescent HCM}

There were no significant age or ethnicity differences between the student-athlete and HCM cohorts (table 1). The HCM cohort did have a slightly higher proportion of males $(72 \%$ vs $60 \%, \mathrm{p}<0.05)$ and a larger average body surface area $(1.92$ vs 1.77, $\mathrm{p}<0.0001)$. As expected, adolescents with HCM satisfied standard ECG criteria for $\mathrm{LVH}, \mathrm{RVH}$ or BVH more often than the student-athlete cohort $(85 \%$ vs $52 \%, \mathrm{p}<0.0001)$. When the sexes were analysed separately, both males and females with HCM had higher rates of meeting voltage criteria for hypertrophy than student-athletes $(90 \%$ vs $78 \%, \mathrm{p}<0.02$ and $73 \%$ vs $15 \%, \mathrm{p}<0.0001$, respectively).

Table 3 compares lead-specific wave measurements between the two cohorts.

A complete list of abnormal ECG findings in each cohort can be found in table 4 .

Significant differences in the frequency of ST-segment depression $(30 \%$ vs $0 \%, \mathrm{p}<0.0001)$, T-wave inversions $(62 \%$ vs $1 \%$, $\mathrm{p}<0.0001)$ and pathological Q-waves $(21 \%$ vs $0 \%, \mathrm{p}<0.0001)$ were found in the HCM cohort as compared to the student-athletes. Seventy-six per cent of patients in the HCM cohort had at least one of these ECG abnormalities compared to $1 \%$ in the student athlete cohort $(\mathrm{p}<0.0001)$. Other ECG findings that were significantly increased in the HCM cohort compared to the student-athletes included left axis deviation ( $21 \%$ vs $0 \%, \mathrm{p}<0.0001)$, right axis deviation $(9 \%$ vs $1 \%$, $\mathrm{p}<0.01)$, prolonged QT $(14 \%$ vs $0 \%, \mathrm{p}<0.0001)$ and pre-
Table 3 Specific examination and ECG measurements

\begin{tabular}{lccc}
\hline Measurement & Student-athletes & Adolescents with HCM & p Value \\
\hline Heart rate (bpm) & $63 \pm 10$ & $66 \pm 12$ & 0.016 \\
Systolic BP (mm Hg) & $111 \pm 14$ & $126 \pm 13$ & $<0.0001$ \\
PR interval (ms) & $154 \pm 2$ & $146 \pm 2$ & 0.005 \\
QRS Duration (ms) & $92 \pm 9$ & $106 \pm 19$ & $<0.0001$ \\
S-Wave V1 (mm) & $12 \pm 6$ & $22 \pm 13$ & $<0.0001$ \\
R-Wave V1 (mm) & $4 \pm 3$ & $6 \pm 7$ & $<0.01$ \\
S-Wave V5 (mm) & $4 \pm 3$ & $7 \pm 7$ & $<0.0001$ \\
R-Wave V5 (mm) & $21 \pm 1$ & $19 \pm 1$ & 0.90 \\
S-Wave V6 (mm) & $2 \pm 2$ & $4 \pm 6$ & 0.0006 \\
R-Wave V6 (mm) & $17 \pm 1$ & $17 \pm 1$ & 0.70 \\
Q-Wave III (mm) & $1.0 \pm 1.0$ & $2.5 \pm 5.4$ & $<0.001$ \\
Q-Wave V6 (mm) & $0.9 \pm 0.9$ & $1.2 \pm 1.8$ & 0.054 \\
R-Wave III (mm) & $10.4 \pm 0.6$ & $11.5 \pm 9.1$ & 0.11 \\
Total V3 (mm) & $22 \pm 8$ & $37 \pm 16$ & $<0.0001$ \\
Total V4 (mm) & $27 \pm 11$ & $34 \pm 15$ & $<0.0001$ \\
QTc $>99 t h$ centile & $0 / 147(1 \%)$ & $21 / 148(14 \%)$ & $<0.0001$ \\
\hline HCM, hypertrophic cardiomyopathy. & &
\end{tabular}

excitation $(12 \%$ vs $0 \%, \mathrm{p}<0.0001)$. An example of an ECG with pre-excitation can be found in figure 1 . Of the 31 patients with left axis deviation, only 3 had no other abnormal finding per Seattle criteria.

\section{ST-segment depression and T-wave inversion}

ST-segment and T-wave abnormalities were further delineated by location for each cohort. ST-segment depression with specific leads can be found in table 5. ST-segment depression was present in none of the student-athlete ECGs. In the HCM cohort, ST-segment depression was most commonly found in the lateral leads (24\%), but was also present in the inferior $(11 \%)$ and anterior leads (9\%).

T-wave inversions with lead localisation can be found in table 5. Abnormal T-wave inversion was most prevalent in the

Table 4 ECG findings

\begin{tabular}{lcrc}
\hline Category & $\begin{array}{l}\text { Student } \\
\text { athletes }\end{array}$ & $\begin{array}{l}\text { Adolescents } \\
\text { with HCM }\end{array}$ & p Value \\
\hline LVH & $45(31 \%)$ & $47(32 \%)$ & 0.83 \\
RVH & $19(13 \%)$ & $34(23 \%)$ & 0.0246 \\
BVH & $13(9 \%)$ & $45(30 \%)$ & $<0.0001$ \\
LVH, RVH, or BVH & $77 / 147(52 \%)$ & $126 / 148(85 \%)$ & $<0.0001$ \\
RAE & $2(1 \%)$ & $4(3 \%)$ & 0.68 \\
LAE & $0(0 \%)$ & $20(14 \%)$ & $<0.0001$ \\
BAE & $0(0 \%)$ & $17(11 \%)$ & $<0.0001$ \\
RAE, LAE or BAE & $2 / 147(1 \%)$ & $41 / 148(28 \%)$ & $<0.0001$ \\
Right axis deviation & $1 / 147(1 \%)$ & $13 / 148(9 \%)$ & 0.001 \\
Left axis deviation & $0 / 147(0 \%)$ & $31 / 148(21 \%)$ & $<0.0001$ \\
ST-segment depression & $0 / 147(0 \%)$ & $44 / 148(30 \%)$ & $<0.0001$ \\
T-wave inversion & $1 / 147(1 \%)$ & $92 / 148(62 \%)$ & $<0.0001$ \\
Pathological Q waves & $0 / 147(0 \%)$ & $31 / 148(21 \%)$ & $<0.0001$ \\
ST-segment depression, & $1 / 147(1 \%)$ & $112 / 148(76 \%)$ & $<0.0001$ \\
T-wave inversion, or & & & \\
pathological Q-waves & & & $<0.0001$ \\
Pre-excitation & $0 / 147(0 \%)$ & $18 / 148(12 \%)$ & $<$
\end{tabular}

BAE, biatrial enlargement; BVH, biventricular hypertrophy; HCM, hypertrophic cardiomyopathy; LAE, left atrial enlargement; LVH, left ventricular hypertrophy; RAE, right atrial enlargement; RVH, right ventricular hypertrophy. 
Figure 1 Example of an ECG with pre-excitation.

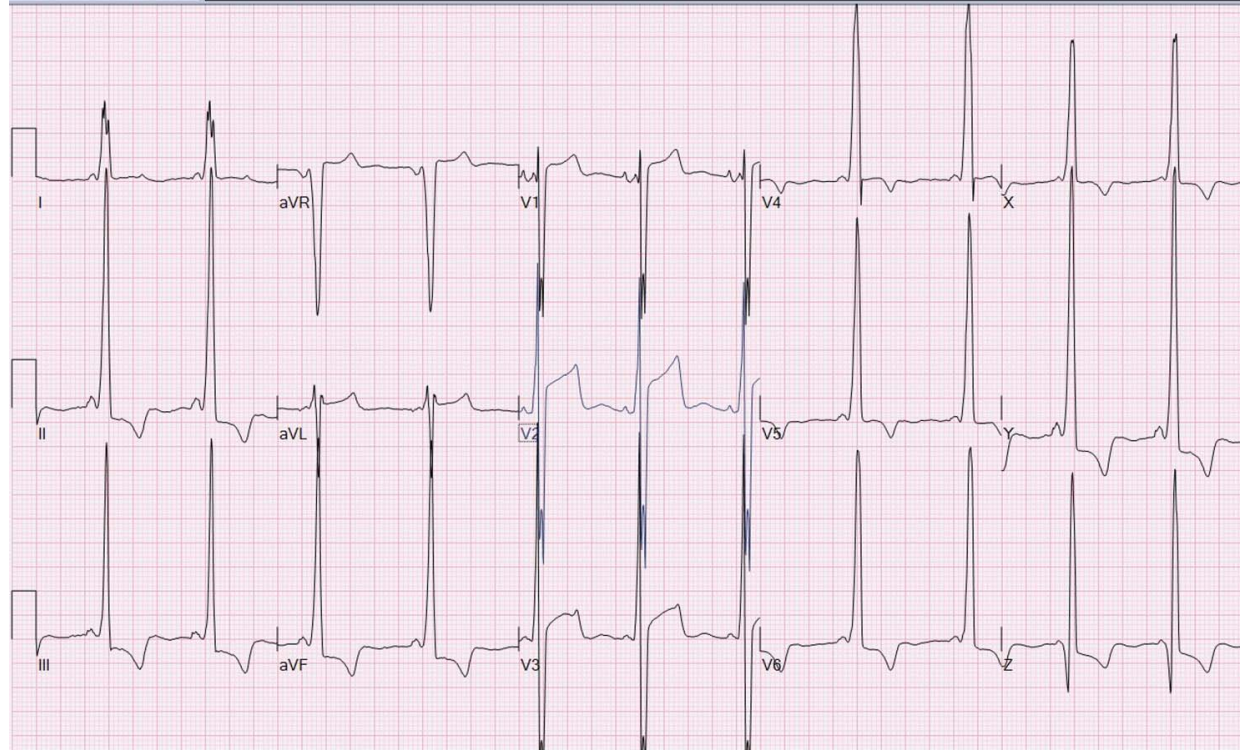

lateral leads (I, aVL, V5, V6, 47\%), but was also common in anterior (V3, V4, 49\%) and inferior leads (II, aVF, 30\%). Only one ECG in the student-athlete cohort had T-wave inversion past V2 and none had inversion in the lateral or limb leads.

\section{ESC and Seattle criteria}

The ECG findings of both the student-athlete and HCM cohorts were stratified according to the ESC and Seattle guidelines for the interpretation of ECGs in athletes. Eighty-nine per cent of the HCM cohort fell into the ESC group 2 category (abnormal) as compared to $24 \%$ of student-athletes $(\mathrm{p}<0.0001)$. Using the Seattle criteria, $84 \%$ of the HCM cohort was placed in the abnormal category compared to $1 \%$ of student-athletes $(p<0.0001)$. Abnormal findings in the student-athlete ECGs can be found in table 6. Thus, the ESC guidelines resulted in a sensitivity and specificity of $88 \%$ and $76 \%$, respectively. The sensitivity and specificity of the Seattle criteria were $84 \%$ and 99\%, respectively. Figures 2 and 3 show examples of abnormal athlete ECGs.

\section{DISCUSSION}

ECG screening of student athletes in the USA is controversial. Some investigators have proposed using ECG screening to reduce the risk of sudden death in athletics. ${ }^{1} 6{ }^{12} \mathrm{HCM}$ is thought to be one of the most common causes of sudden death

Table 5 ST-segment depression and T-wave inversions with location

\begin{tabular}{lrrr}
\hline Leads & Athlete cohort & HCM cohort & p Value \\
\hline ST depression & $(0 \%)$ & $44(30 \%)$ & $<0.0001$ \\
Anterior (V1-V4) & $(0 \%)$ & $13(9 \%)$ & 0.0002 \\
Inferior (II, aVF) & $(0 \%)$ & $16(11 \%)$ & $<0.0001$ \\
Lateral (I, aVL, V5, V6) & $(0 \%)$ & $36(24 \%)$ & $<0.0001$ \\
T-wave inversion & $1 / 147(1 \%)$ & $92 / 148(62 \%)$ & $<0.0001$ \\
Abnormal anterior (V2-V4) & $1(1 \%)$ & $53(36 \%)$ & $<0.0001$ \\
Inferior (II, aVF) & $0(0 \%)$ & $44(30 \%)$ & $<0.0001$ \\
Lateral (I, aVL,V5, V6 & $0(0 \%)$ & $79(53 \%)$ & $<0.0001$ \\
\hline
\end{tabular}

Note that some patients had findings in more than one location. in the young. ${ }^{1} 1520$ Here, we describe a cohort of young elite high school athletes with comparison to a cohort of adolescents with HCM.

\section{LVH/RVH criteria}

In the student-athlete cohort, roughly half of all subjects met voltage criteria for $\mathrm{LVH}, \mathrm{RVH}$ or BVH. The rates of $\mathrm{LVH}$ and RVH are similar to those found in prior studies. ${ }^{21-24}$ The male athletes were five times more likely to meet these criteria than female athletes. This gender discrepancy has also been previously reported to varying degrees. ${ }^{11} 23$ This observation again underscores the critical importance of excluding voltage criteria for hypertrophy as a sufficient finding in isolation when screening athletes for potential heart disease. Using isolated voltage criteria will result in an unacceptable false-positive rate and the frequency of subsequent referrals will be unnecessarily high. In female athletes, hypertrophy is a less common finding; thus, clinicians may want to be more cautious with a female adolescent meeting voltage criteria for hypertrophy.

\section{ECG stratification}

The most useful ECG findings for distinguishing an adolescent with HCM from a student-athlete with a structurally normal heart were ST-segment depression, T-wave inversion or pathological Q-waves, as well as total V3 and V4 QRS voltage deflections. The value of assessing total voltage in V3 or V4 in athletes as a potential marker of pathological hypertrophy requires further investigation. Other abnormalities that were much more common in the HCM cohort included preexcitation/Wolff-Parkinson-White (WPW), left or right axis deviation, left or bilateral atrial enlargement and prolonged QT

Table 6 Abnormal student-athlete ECGs according to Seattle criteria

\begin{tabular}{llllll}
\hline Student & Age & Sport & Abnormality & Location & Ethnicity \\
\hline 1 & 16 & Ice hockey & T-wave inversion & V1, V2 and V3 & Unknown \\
2 & 14 & Ice hockey & RVH+RAD & NA & White \\
\hline \multicolumn{4}{l}{ RAD, right axis deviation; RVH, right ventricular hypertrophy; NA, not applicable. }
\end{tabular}


Figure 2 Abnormal athlete ECG corresponding with student 1 in table 4. There is T-wave inversion beyond V2 which makes this abnormal per European Society of Cardiology and Seattle criteria.

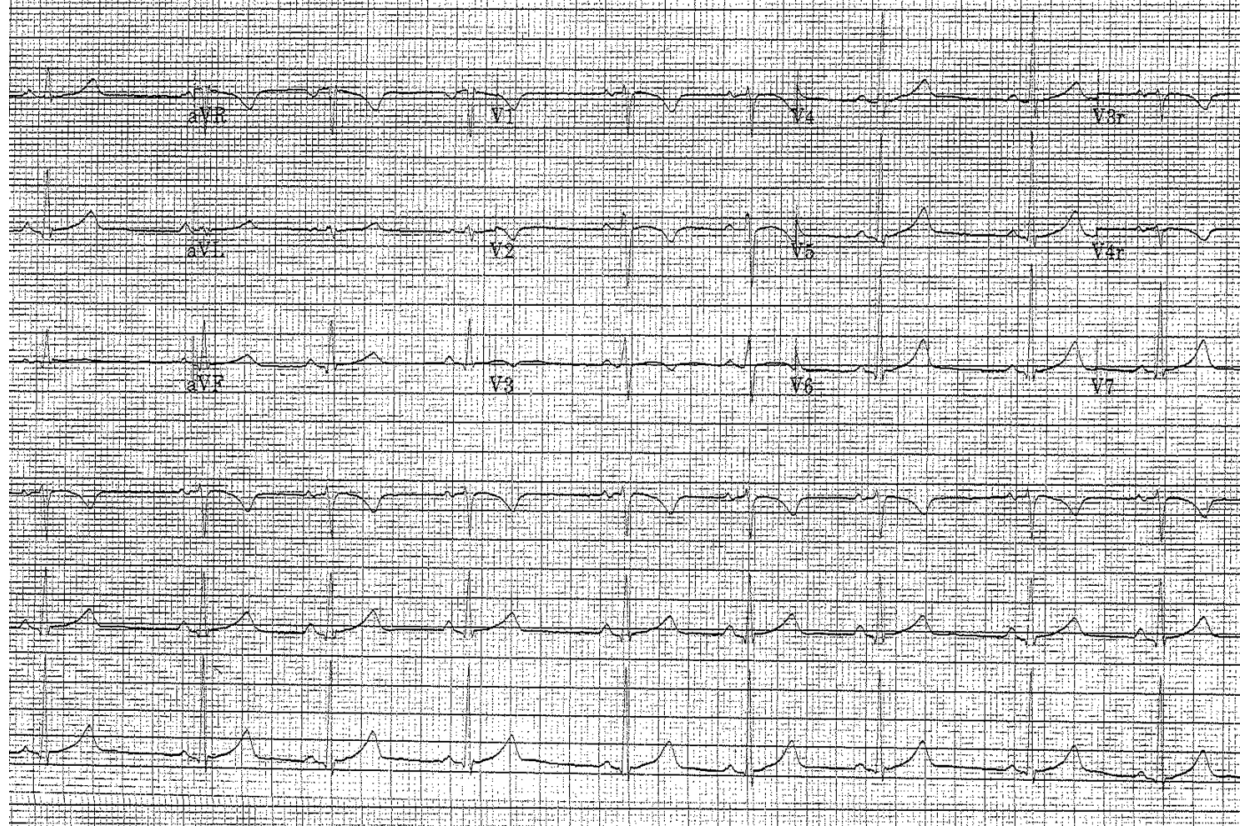

intervals. Pre-excitation and accessory pathways have been described in patients with HCM. $^{25}$

All of these abnormalities are found in the ESC and Seattle criteria as suggestive for a serious underlying cardiac abnormality. ${ }^{12}$ LVH in isolation was not more common in the HCM group, primarily because many in the HCM cohort met criteria or BVH. LV voltage has been shown to be poorly correlated and with low specificity for LV mass. ${ }^{26-28}$

\section{T-wave inversion}

T-wave inversion is more common in the HCM population and is very concerning on ECG for underlying cardiac pathology. ${ }^{12} 1329$ T-wave inversion is much less common in the athlete ECG. ${ }^{11} 22{ }^{24}$ In our study, T-wave inversion was present in over half of all ECGs in the HCM cohort in the lateral leads and nearly one-third in the inferior leads. No student-athlete had T-wave inversion present in the inferior or lateral leads. One-third of the HCM cohort had T-wave inversion in the anterior leads beyond V2. In all but one subject in the student-athlete cohort, T-wave inversion in V2 was accompanied only by inversion in V1. In high school athletes, T-wave inversion in the inferior, lateral or anterior leads (excluding V1 and V2) should be viewed as suspicious for underlying cardiac pathology.

\section{ST-segment abnormalities}

No student-athlete demonstrated ST-segment depression. In contrast $30 \%$ of patients with HCM exhibited ST-segment depression. ST-segment depression has been shown to be very prevalent in patients with $\mathrm{HCM}^{26} 29$ and warrants further investigation if found in asymptomatic athletes.

\section{ESC/Seattle criteria}

Both the ESC and the Seattle criteria were able to further stratify the student-athlete and HCM cohorts. Eighty-eight per cent of HCM adolescents were categorised as group 2 (abnormal) according to the ESC guidelines as opposed to $24 \%$ of student-athletes. This frequency for the student athlete group is similar to other previously published studies. ${ }^{21}{ }^{29-31}$ The Seattle criteria had a slightly lower sensitivity for identifying HCM adolescents by an abnormal ECG classification (84\%). However, only $1 \%$ of student-athletes were categorised as abnormal (false
Figure 3 Abnormal athlete ECG corresponding to student 2 in table 4. This ECG demonstrates right ventricular hypertrophy with right axis deviation.

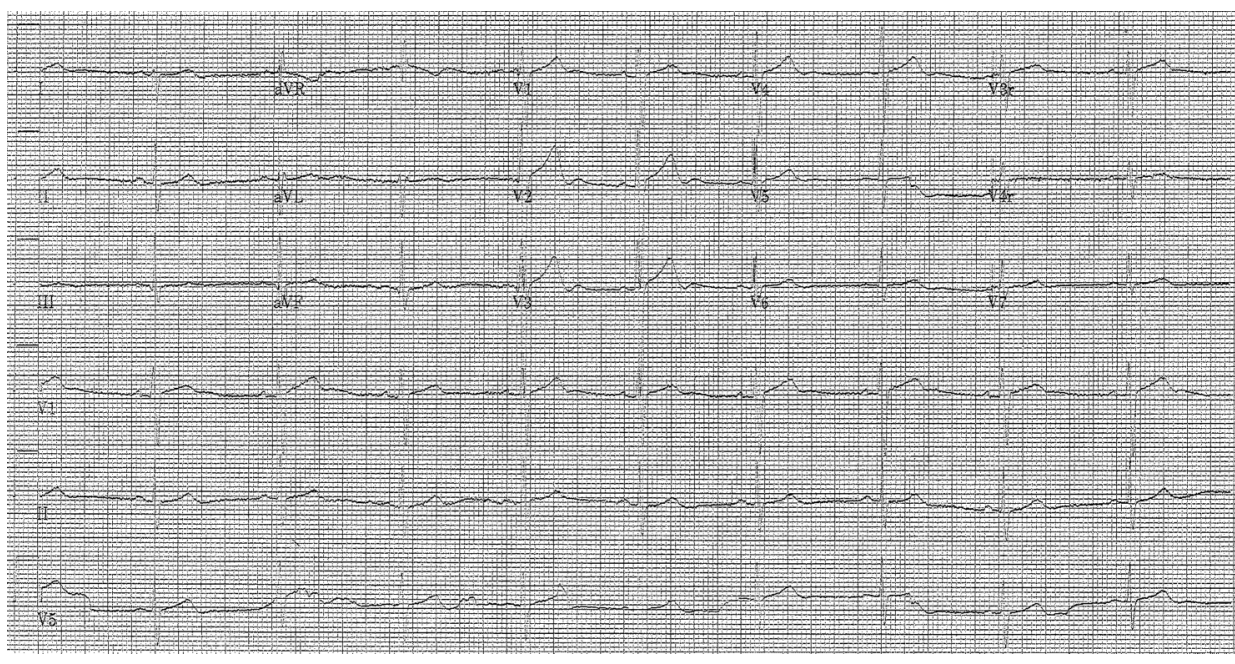


positive). The main reason for this discrepancy was the difference in definition of RVH between the ESC and Seattle criteria, as well as the short QT cut-off $(<380 \mathrm{~ms}$ in the ESC criteria vs $<320 \mathrm{~ms}$ in the Seattle criteria). This enhanced specificity has been reported previously and this cohort provides independent confirmation of that observation. ${ }^{29}$

Our study did show a $10-15 \%$ false-negative rate with both the ESC and Seattle criteria. This is in contrast to Sheikh et $a^{29}$ who found that both criteria were successful in identifying $98 \%$ of their HCM cohort. One major difference with their HCM cohort was that they were athletes with HCM. One might hypothesise that HCM hearts that have been exposed to exercise might be more likely to exhibit abnormalities. In general, approximately $10 \%$ of patients with HCM will have an entirely normal ECG consistent with the false-negative rate found in this study. ${ }^{32-34}$

Using the ESC criteria, roughly one in four student athlete ECGs were considered abnormal and would require further testing. In our cohort, the Seattle criteria increased the specificity and greatly reduced the number of adolescents requiring further testing (1 in 74).

\section{LIMITATIONS}

This study compares elite athletes in a Minnesota high school to a cohort of patients with HCM who were seen at a tertiary care hospital in Minnesota. Although they are located relatively close to each other geographically, many of the patients with HCM came from other regions of the USA or even from other countries. Although both cohorts were predominantly Caucasian and not significantly different, ethnicity data was not known on roughly $25 \%$ of each cohort, including two of the ECGs determined abnormal by Seattle criteria. Thus, our findings may not be applicable to older athlete populations or cohorts with more ethnic diversity. Although there were no significant age differences between the two cohorts, there was a slight difference in gender makeup and body surface area. Our attempt was to gather data on our HCM cohort at the time of diagnosis, although this was not always possible as some of the patients were referred from other institutions with a diagnosis already, or were diagnosed prior to the minimum age for our inclusion criteria. This HCM cohort was also defined retrospectively which may limit generalisability. Lastly, our student athlete cohort was relatively small and may not have captured the range of ECG findings in a larger or more diverse population of athletes.

\section{CONCLUSIONS}

ECGs have been debated as an effective tool for screening for the early detection of heart conditions predisposing to sudden death in athletes. Among elite high school athletes with echocardiographically confirmed normal hearts, over half of all athletes satisfied standard voltage criteria for ventricular hypertrophy. The ESC and Seattle criteria are more effective in differentiating patients with underlying cardiac pathology based on ECG when compared to LVH criteria alone, with the Seattle criteria being much more specific. The presence of ST-segment depression, T-wave inversion and pathological Q-waves in any patient mandates further evaluation for the possibility of an underlying cardiomyopathy. Both ESC and Seattle criteria successfully stratified the student-athlete and HCM cohorts, however each had a false-negative rate $>10 \%$ for the HCM cohort consistent with prior studies. The false-positive rate was significantly lower using the Seattle criteria.

\section{What are the findings?}

- Over $50 \%$ of elite high school athletes with echocardiographically confirmed normal hearts satisfied voltage criteria for ventricular hypertrophy.

- Pathological Q-waves, T-wave inversion or ST-segment depression were most helpful in distinguishing adolescents with hypertrophic cardiomyopathy (HCM) from normal athletes.

- Both the Seattle criteria and ESC criteria had a false-negative rate greater than $10 \%$ for adolescents with HCM.

\section{How might it impact on clinical practice in the future?}

- Voltage criteria for hypertrophy show marked overlap between normal high school athletes and adolescents with HCM and thus is a good distinguisher of pathological left ventricular hypertrophy. Voltage criteria should continue to be excluded when evaluating athletes in ECG screening programmes

- The presence of pathological Q-waves, T wave inversion or ST-segment depression in any patient mandates further evaluation for the possibility of an underlying cardiomyopathy.

Acknowledgements The authors would like to acknowledge and thank the high school students and their families who participated in this study.

Funding Funding was provided by Todd and Karen Wanek Programme for Hypoplastic Left Heart syndrome, Mayo Clinic Foundation. The echocardiography machine used in this programme was supplied by the General Electric Corporation.

Competing interests MJA is a consultant for Boston Scientific, Gilead Sciences, Medtronic and St. Jude Medical Inc, and receives royalties from Transgenomic for FAMILION-LQTS and FAMILION-CPVT genetic tests. BCC is a consultant for Medtronic and on the Board of Directors for Mayo Support Services Texas.

Ethics approval Mayo Clinic Institutional Review Board.

Provenance and peer review Not commissioned; externally peer reviewed.

\section{REFERENCES}

1 Maron BJ, Thompson PD, Ackerman MJ, et al. Recommendations and considerations related to preparticipation screening for cardiovascular abnormalities in competitive athletes: 2007 update: a scientific statement from the American Heart Association Council on Nutrition, Physical Activity, and Metabolism: endorsed by the American College of Cardiology Foundation. Circulation 2007;115:1643-455.

2 Myerburg RJ, Vetter VL. Electrocardiograms should be included in preparticipation screening of athletes. Circulation 2007;116:2616-26; discussion 26.

3 Corrado D, Basso C, Pavei A, et al. Trends in sudden cardiovascular death in young competitive athletes after implementation of a preparticipation screening program. JAMA 2006;296:1593-601.

4 Steinvil A, Chundadze T, Zeltser D, et al. Mandatory electrocardiographic screening of athletes to reduce their risk for sudden death proven fact or wishful thinking?. J Am Coll Cardiol 2011;57:1291-6.

5 Marek J, Bufalino V, Davis J, et al. Feasibility and findings of large-scale electrocardiographic screening in young adults: data from 32,561 subjects. Heart Rhythm 2011;8:1555-9.

6 Vetter VL, Dugan N, Guo R, et al. A pilot study of the feasibility of heart screening for sudden cardiac arrest in healthy children. Am Heart J 2011;161: 1000-6.e3.

7 Pelliccia A, Corrado D. The Israel screening failure analyzing the data to understand the results. J Am Coll Cardiol 2011;58:989-90; author reply 91-2. 
8 Drezner JA, Harmon KG, Borjesson M. Incidence of sudden cardiac death in athletes: where did the science go? Br J Sports Med 2011:45:947-8.

9 Maron BJ, Friedman RA, Kligfield P, et al. Assessment of the 12-lead electrocardiogram as a screening test for detection of cardiovascular disease in healthy general populations of young people (12-25 years of age): a scientific statement from the American Heart Association and the American College of Cardiology. J Am Coll Cardiol 2014;64: 1479-514.

10 Maron BJ. Distinguishing hypertrophic cardiomyopathy from athlete's heart physiological remodelling: clinical significance, diagnostic strategies and implications for preparticipation screening. Br J Sports Med 2009;43:649-56.

11 Pelliccia A, Maron BJ, Culasso F, et al. Clinical significance of abnormal electrocardiographic patterns in trained athletes. Circulation 2000;102: 278-84.

12 Corrado D, Pelliccia A, Heidbuchel $\mathrm{H}$, et al. Recommendations for interpretation of 12-lead electrocardiogram in the athlete. Eur Heart J 2010;31:243-59.

13 Drezner JA, Ackerman MJ, Anderson J, et al. Electrocardiographic interpretation in athletes: the 'Seattle criteria'. Br J Sports Med 2013;47:122-4.

14 Riding NR, Salah O, Sharma S, et al. ECG and morphologic adaptations in Arabic athletes: are the European Society of Cardiology's recommendations for the interpretation of the 12-lead ECG appropriate for this ethnicity?. Br J Sports Med 2014;48:1138-43.

15 Maron BJ. Hypertrophic cardiomyopathy: a systematic review. JAMA 2002:287:1308-20

16 Gersh BJ, Maron BJ, Bonow RO, et al. 2011 ACCF/AHA Guideline for the Diagnosis and Treatment of Hypertrophic Cardiomyopathy: a report of the American College of Cardiology Foundation/American Heart Association Task Force on Practice Guidelines. Developed in collaboration with the American Association for Thoracic Surgery, American Society of Echocardiography, American Society of Nuclear Cardiology, Heart Failure Society of America, Heart Rhythm Society, Society for Cardiovascular Angiography and Interventions, and Society of Thoracic Surgeons. J Am Coll Cardiol 2011;58:e212-60.

17 Maron BJ, Spirito P, Shen WK, et al. Implantable cardioverter-defibrillators and prevention of sudden cardiac death in hypertrophic cardiomyopathy. JAMA 2007;298:405-12.

18 McKenna WJ, Goodwin JF. The natural history of hypertrophic cardiomyopathy. Curr Probl Cardiol 1981;6:1-26.

19 Bazett $H$. An analysis of the time-relations of electrocardiograms. Heart 1920:353-70.

20 Maron BJ. Sudden death in young athletes. N Engl J Med 2003;349:1064-75.
21 Chandra N, Papadakis M, Duschl J, et al. Comparing the prevalence of ECG abnormalities between young athletes and non-athletes: the implications for a nationwide screening program. Circulation 2010;122:A16692.

22 Papadakis M, Basavarajaiah S, Rawlins J, et al. Prevalence and significance of T-wave inversions in predominantly Caucasian adolescent athletes. Eur Heart J 2009;30:1728-35.

23 Sharma $S$, Whyte $G$, Elliott $P$, et al. Electrocardiographic changes in 1000 highly trained junior elite athletes. Br J Sports Med 1999:33:319-24.

24 Sheikh N, Papadakis M, Carre F, et al. Cardiac adaptation to exercise in adolescent athletes of African ethnicity: an emergent elite athletic population. $\mathrm{Br} J$ Sports Med 2013:47:585-92.

25 Fananapazir L, Tracy CM, Leon MB, et al. Electrophysiologic abnormalities in patients with hypertrophic cardiomyopathy. A consecutive analysis in 155 patients Circulation 1989;80:1259-68

26 Guerrier K, Anderson JB, Pratt J, et al. Correlation of precordial voltages to left ventricular mass on echocardiogram in adolescent patients with hypertrophic cardiomyopathy compared with that in adolescent athletes. Am J Cardiol 2015;115:956-61.

27 Czosek RJ, Cnota JF, Knilans TK, et al. Relationship between echocardiographic LV mass and ECG based left ventricular voltages in an adolescent population: related or random? Pacing Clin Electrophysiol 2014;37:1133-40.

28 Dipchand Al, McCrindle BW, Gow RM, et al. Accuracy of surface electrocardiograms for differentiating children with hypertrophic cardiomyopathy from normal children. Am J Cardiol 1999:83:628-30, A10

29 Sheikh N, Papadakis M, Ghani S, et al. Comparison of electrocardiographic criteria for the detection of cardiac abnormalities in elite black and white athletes. Circulation 2014;129:1637-49.

30 Snoek JA, Jongman JK, Brandon T, et al. Performance of the Lausanne questionnaire and the 2010 European Society of Cardiology criteria for ECG interpretation in athletes. Eur J Prev Cardiol 2015;22:397-405.

31 Brosnan M, La Gerche A, Kalman J, et al. The Seattle Criteria increase the specificity of preparticipation ECG screening among elite athletes. $\mathrm{Br} J$ Sports Med 2014:48:1144-50.

32 Rowin EJ, Maron BJ, Appelbaum E, et al. Significance of false negative electrocardiograms in preparticipation screening of athletes for hypertrophic cardiomyopathy. Am J Cardiol 2012;110:1027-32.

33 Ryan MP, Cleland JG, French JA, et al. The standard electrocardiogram as a screening test for hypertrophic cardiomyopathy. Am J Cardiol 1995;76:689-94.

34 Maron BJ, Roberts WC, Epstein SE. Sudden death in hypertrophic cardiomyopathy: a profile of 78 patients. Circulation 1982;65:1388-94. 